\title{
A Terra é de vocês! Compreendendo a efetivação do direito ao Território no seio do povo indígena Puyanawa
}

\author{
The Land is yours! Understanding the implementation \\ Puyanawa Rights to the Territory
}

Jósimo da Costa Constant ${ }^{1}$

DOI 10.26512/rbla.v11i02.28444

Recebido em novembro/2019 e aceito em dezembro/2019.

Resumo

Este estudo tem por objetivo analisar aspectos da política necessária à demarcação da Terra Indígena (TI) Puyanawa. Reúnem-se elementos da história, memória, assim como relatos de grandes protagonistas que participaram de forma ativa no processo de demarcação em pauta. O estudo contribui com novos elementos sobre a história de um povo que teve suas relações sociais quebradas, e para o qual a terra é o principal elemento que lhes identifica como povo diferenciado e propagador de uma cultura milenar que, aos poucos, têm-se estruturado de forma surpreendente. Todos os pontos apresentados e questionados concluem que sempre houve por parte do povo Puyanawa o sentimento de propriedade e ambivalência indígena. A luta e o protagonismo ũdi kuĩ , bem como o papel dos profissionais não indígenas, serão os principais focos do presente artigo.

Palavras-chave: Puyanawa. Demarcação de Terras Indígenas. História, Protagonismo Indígena.

\begin{abstract}
This paper aims to analyze the processes and gather the elements, a policy that required the demarcation of Puyanawa Indigenous Land (TI). Objective here to gather history, memory and reports of great protagonists who recorded actively and effectively in the process of demarcation. To make a deeper analysis of the history of a people whose social relations were broken, is essential. Thus, a terrain for the Puyanawa people is the main element that identifies as a differentiated people and propagator of a millenary culture gradually structuring in a surprising way. All points presented and questioned conclude that there has
\end{abstract}

1 Doutorando no Programa de Antropologia Social da Universidade Federal do Rio de Janeiro. Graduado em antropologia pela Universidade de Brasília é Mestre em Sociologia e Mestre em Direitos Humanos e Cidadania pela Universidade de Brasília. josimo.constant@ gmail.com 
always been from the Puyanawa people a sense of indigenous ownership and ambivalence. The $\tilde{u} d i$ kui struggle and protagonism, as well as the role of non-indigenous professionals, will be the main focus of this short article.

Keywords: Puyanawa. Demarcation of Indigenous Lands. History, Indigenous Protagonism.

\section{Introdução}

Sou um indígena da etnia Puyanawa (ũdi kuĩ), meu povo foi severamente colonizado, escravizado e passamos muitos anos sofrendo imensas censuras nas mãos dos "patrões da borracha". Objetivo, neste trabalho, apresentar alguns pontos fundamentais sobre o processo de demarcação da Terra Indígena (TI) Puyanawa. Para escrever este artigo, precisei analisar e me apoiar no fazer etnográfico, acessando ângulos, formas, potencialidades e propósitos da antropologia, assim como, documentos, imagens, e realizar uma profunda navegação serena na memória daqueles que participaram deste processo, principalmente os anciões de meu povo.

Nasci em 1989, na beira do igarapé Grande (Behkua), um pouco no contexto dos costumes tradicionais Puyanawa, mas meu crescimento foi cercado de imensos desafios, pois ainda guardávamos com grande pavor as fortes sequelas da colonização. Estávamos dando os primeiros passos para efetivar o processo de retomada da nossa terra, porém, essa conquista representou também inúmeras lutas para a consolidação do nosso direito. No início do ano de 1990, ainda existiam alguns indígenas que tinham vindo da mata ${ }^{2}$, como: Prudente de Morais, Antima, Antônio Jardim, Alberto Itxuway e Joana (Hanna) Mãdaita, última indígena que ainda carregava no rosto as marcas do pente ${ }^{3}$ Puyanawa.

Hoje em dia, como antropólogo formado e procurando exercer o meu papel de entender, preservar e até mesmo salvaguardar nossa história, é que estou desenvolvendo a teoria de que, para morar na terra, houve todo um processo de luta e resistência dos antigos que bravamente resistiram para que nossa história e cultura não fossem exterminadas.

Logo no início da colonização, que se iniciou no ano 1913 com a captura, sequestro do grupo e o assassinato do cacique tradicional (yura kaya) Wêwakãy, passamos pelos mais cruéis castigos, imposições e proibições sob o comando de Mâncio Agostinho de Lima, que recebeu a patente de coronel do presidente Hermes da Fonseca, em 1912, pelos seus "relevantes serviços". Como afirma Rosso, "Ao longo do processo colonizador, os povos indígenas sofreram um longo processo de dominação, extermínio, discriminação e invisibilidade nos cenários políticos, econômicos, sociais, educacionais, culturais" (Rosso

2 Vindos da mata: Que viviam na floresta antes do contato com os não-índios.

3 Pente: marcação tradicional feita dos 8 aos 10 anos de idade no rosto das crianças Puyanawa. 
2012:60).

\section{Sobre o meu povo ũdi kuĩ}

Precisamos primeiramente entender a cosmologia que navega a "metáfora das flechas ancestrais". Todo universo era composto por infinitas flechas, ou seja, fumaças $(k u \tilde{l})$, seres que vagavam pelo mundo. Era um período de imensos zumbidos, barulhos e lutas entre os seres do bem (iũxĩ mãsa) e os seres do mal (iũxĩ bitxa). O barulho era semelhante ao de grandes enxames de moscas em reprodução ou devorando carniça apodrecida na mata. É na atração das cargas de sinais contrários carregadas de energias positivas e negativas, que a fumaça ganha cor e se materializa nos primeiros seres que até aí ainda não eram humanos (Constant 2018).

Nós, Puyanawa (gente do sapo), somos uma etnia indígena que antes da chegada dos exploradores da borracha, habitávamos as margens do Rio Juruá. Segundo os mais velhos, derivamos da junção do sapo e da folha. Acreditamos que somos descendentes do sapo que virou gente. Desta forma, Puya + náwa quer dizer povo ou gente do sapo. Abaixo segue um pequeno trecho da narrativa feita na voz da titia (yaya) Railda Mãdailta (yaya âwi Mãdaita), 87 anos:

A folha de embaúba foi machucada, soprada e apareceu muita gente. A folha de embaúba parecia com cabelo negro bem agarradinho. A mesma coisa foi feita com uma capemba ${ }^{4}$ que apodreceu. Quando apodreceu, viraram gente e se chamaram Puyanawa. Outra capemba apodreceu e viraram tudo sapo, sapinho miúdo. Assim, somos Puyanawa, sapo que virou gente.

Após a chegada dos exploradores, meus antepassados migraram para uma região chamada Paraná dos Mouras, que fica às margens do Rio Juruá. A língua Puyanawa é uma língua da família linguística Pano, chamada pelos falantes Puyanawa de "Vãda kuĩ/Dukũ vãda kayanũ", língua verdadeira. Hoje em dia, somos cerca de 670 pessoas, vivemos em duas grandes aldeias: aldeia Barão e aldeia Ipiranga, num território com cerca de $24.000 \mathrm{~km}^{2}$. As duas aldeias são separadas apenas por um Igarapé que chamamos de Igarapé do Barão (Behkua). Ambas estão situadas no município de Mâncio Lima, as margens dos rios Môa e Japiim, próximo à fronteira com o Peru.

\section{Período do Cativeiro}

Nossa história é marcada pela presença do coronel da borracha denominado Mâncio Lima, que dá nome ao município, que explorou meu povo, usurpou

4 Capemba: folha larga e consistente que se desprende do mangará. 
nosso território e tentou nos dominar por meio da mão-de-obra escrava, embora tenhamos resistido e conseguido a demarcação da nossa Terra Indígena e assim, retomar nossas vidas. Vivemos cativos desse coronel durante o que ficou conhecido como período do "ciclo da borracha".

Segundo informações da titia (yaya) Railda Mãdaita, e o cacique emérito, Mario Hawê, o processo de colonização aumentou mesmo no ano de 1916, com o assassinato do cacique Wêwakãy. A morte desse cacique da linhagem tradicional representou um marco na vida de cada um dos Puyanawa, que com medo da morte e dos severos castigos ameaçadores, se rendeu. Wêwakãy representa também o sentimento de resistência e liberdade, pois vendo toda a tragédia pela qual estava passando nosso povo, resolveu fugir e não se submeter às pesadas regras de Mâncio Lima. Vejamos abaixo um trecho do artigo de Rubéns de Lima, filho de Mâncio Lima, sobre a captura e a morte do tuxawas:

"No que se refere à atração dos índios à convivência com os civilizados, a versão conhecida é a de que ela se tornou indispensável, para impedir as depredações que os poianauas faziam nas barracas dos seringueiros. Foi realizada com uso de intérprete e oferendas. Poucos índios não se deixaram atrair e se tornaram agressivos. A morte do tuxaua pelos empregados do seringal foi em legítima defesa" (Lima 1983: 2).

Antigamente, tínhamos a prática do canibalismo funerário, ou seja, quando morria algum membro do grupo, queimávamos o corpo do falecido, incinerávamos seus ossos e bebíamos com mingau (pasma) de banana, inhame, etc. Aquela era uma cerimônia extremamente restrita. $\mathrm{O}$ cacique da linhagem tradicional foi o último que passou por esse antigo ritual. Após sua morte, alguns indígenas foram até seu corpo que já estava em grande parte consumido por urubus (ixmĩ/xiari), pegaram seus ossos, incineraram, choraram e beberam com mingau.

Mâncio Lima soube daquele ritual e fez várias interrogações, mas o povo com medo não quis revelar o acontecido. Desde aquele dia em diante, o coronel disse que iria punir rigorosamente quem ousasse continuar com aquela prática. Dominados pelo medo, os Puyanawa resolveram abandonar quase todas as práticas antigas, inclusive a língua materna, que atualmente encontra-se em via de extinção, dado o reduzido número de falantes ativos.

O que estou focalizando aqui é o processo de luta que se fez para podermos ter uma terra demarcada e reconhecida pelo estado brasileiro. Por isso, fazse necessário apresentar um pouco da história sobre a égide e o sentimento Puyanawa. Depois da captura e o cruel assassinato do cacique tradicional (yura kaya ũdi kuĩ), fomos transferidos do nosso lugar de origem, Paraná do Moura, para o seringal São Francisco, depois para o Tapiri do Arroz, onde passamos

5 Txawa: cacique, chefe. 
anos. De lá, fomos para a colocação da Maloca, onde o sarampo seguido de uma epidemia de gripe matou vários membros do grupo.

Segundo titia (yaya) Railda Mãdaita, alguém informou para Mâncio Lima, que o povo estava ligeiramente morrendo porque viviam todos juntos numa grande maloca (tapassa). Assim, o coronel ordenou que o povo se separasse e morasse em casas menores (uta). Diante disso, os cruéis castigos começaram e perduraram por muitos anos. Logo no início da colonização, os homens foram separados das mulheres e mandados para as colocações para cortar seringa. As mulheres carregavam enormes pélas ${ }^{6}$ de borracha nas costas, além disso, muitas sofreram estupros ou se submetiam ao sexo obrigatório para ganharem roupas e outros mantimentos.

Em uma entrevista com o senhor Jorge Constant, meu pai ${ }^{7}$, ele me contou com mais detalhes sobre o período do cativeiro. Poitxo relatou que Mâncio Lima colocou os índios para trabalhar duramente e isso era algo que eles não eram acostumados a fazer, e-logo, o povo não se adaptou bem ao trabalho forçado. $\mathrm{O}$ trabalho faz parte do viver, não é obrigatório, mas está inserido na dinâmica da vida, mas o trabalho escravo era algo totalmente estranho para os Puyanawa.

Através do sistema de aviamento, que envolvia o seringal, o seringalista e o seringueiro, é que nasceu o período do cativeiro. Sobre esse sistema, Meira (2017), assim o define:

O sistema de aviamento constituiu-se na Amazônia como um modelo que implica a formação de uma cadeia de escambo entre, de um lado, comerciantes/patrões e, de outro, produtores/fregueses, ambos situados, respectivamente, como elos de uma corrente, entre dois polos sociopolíticos hierárquicos, marcados por relações de dominação e dependência em função da dívida estabelecida (Meira 2017: 33).

Sobre o período de implantação desse sistema nos seringais do Acre, Poitxo, um homem puyanawa de 65 anos relata o seguinte:

Começou o trabalho forçado né. O coronel dividiu as tarefas de trabalho para cada grupo de pessoas, pois tinha o grupo dos caçadores, grupo dos vaqueiros, grupo dos trabalhadores da agricultura, grupo dos pescadores, grupo dos seringueiros e cada um desses grupos tinha um tanto de pessoas, tanto índios como não-índios. As mulheres, as índias eram para carregar carga trabalhando apanhando café, arroz, feijão milho, trabalhavam na farinhada, nas casas de farinha, então esse era o trabalho das mulheres. Os homens eram seringueiros, aqueles mais novos, e os mais velhos que aguentavam caçar eram caçadores como meu avô e outros, eram caçadores. Outros trabalhavam somente na

6 Pélas: Bolas de borracha.

7 Na língua materna, o seu nome é "Poitxo", aruá de gapó. 
agricultura. (Poitxo, entrevista 2016)

Sobre as colocações de Poitxo, reitero e reforço as ideias de Durkheim, quando este escreve Da Divisão Social do Trabalho. Houve uma constante modificação na estrutura social Puyanawa, ocorrida com o advento da sociedade moderna. Os conflitos ocasionados pela desordem geraram enormes conflitos para o meu povo, assim, as partes que formam o sapo (puya) deixaram de funcionar. É por isso que para Durkheim, "a sociedade é semelhante a um corpo vivo, cada órgão cumpre uma função, ou seja, as partes (os fatos sociais) existem em função do todo, a sociedade" (Durkheim, 1897).

Um olhar histórico sobre o povo Puyanawa propicia a compreensão do processo colonialista a que foram submetidos, seja pelas mãos do Coronel Mâncio Lima, com o auxílio de Antônio Bastos ${ }^{8}$, e que se expressa em forma do poder que se perpetuou por quase um século, seja pelas políticas vigentes na época. Tal processo marca o início da hibridização da identidade indígena Puyanawa, responsável por tirar a língua puyanawa do contexto diário, substituindo costumes, tradições, hábitos, crenças e danças, de forma que muitos jovens, atualmente, sentem vergonha de ser índio.

Há uma estreita relação entre memória e história, cultura e poder, segundo Giroux (1995), visto que:

... ao historicizar a cultura e problematizar o conhecimento ... recai a ... necessidade de uma política cultural que questione a relação entre conhecimento e autoridade, a forma como essa relação é estabelecida e que conexão ela tem com regimes dominantes de representação (Giroux 1995: 132-133).

\section{Processo de Identificação, Delimitação e Demarcação da Terra Puyanawa}

Compreender o processo de demarcação da Terra Indígena (TI) Puyanawa é uma inquietação que já me persegue por muitos anos. Tenho procurado ouvir e sentir minuciosamente os anciões de meu povo, suas histórias e participações para consolidação de um direito ancestral. Minha primeira flecha foi lançada no ano de 2014, quando entrei em contato com o antropólogo Terri Vale de Aquino, que me disse encorajadoras palavras: "Não posso lhe dar o peixe, mas posso lhe ensinar a pescar, a fazer uma pesquisa séria sobre seu povo, que passou a viver a partir do início da década de 1980, quando começou a se organizar no movimento das cooperativas indígenas, que o libertou do cativeiro dos patrões do seringal".

8 Antônio Bastos: Foi o maior catequizador de indígenas no Acre. Tinha facilidade de manter contato com os grupos indígenas, conhecia muito bem a língua dos povos. 
Terri pediu para que eu fosse atrás das pessoas que participaram ativamente do processo de retomada da terra. Naquela época, sendo um aspirante da antropologia, ainda não conhecia muito bem as suas potencialidades, mas fiz pequenas entrevistas com algumas pessoas do povo. Hoje tenho a noção que é preciso buscar e entender cada pulo minucioso que o sapo deu para sair da boca da serpente da colonização. Numa entrevista que fiz com o atual cacique emérito, Mario Hawê, ele disse que foi escolhido numa reunião para liderar o povo. Conforme me narrou, Terri Aquino disse para ele: "Bom Mario, essa terra é de vocês, porém, esse direito, vocês têm que ir buscar muito longe".

No dia 08/09/2017, estive em Rio Branco buscando informações para a construção da minha dissertação de mestrado afim de obter o grau de mestre em Direitos Humanos pela Universidade de Brasília (UnB). Tive a oportunidade de conversar e entrevistar pessoalmente o grande sertanista Antônio Macêdo. Ele foi muitos anos casado com a já falecida Renilda Mãdaita, filha da titia (yaya) Railda Mãdaita. Na célebre visita ao sertanista, titia (yaya) estava por lá, e a pedido de Macêdo, comecei a estudar os fundamentos da narrativa da criação Puyanawa e interpretar seus informes.

Seguem as renomadas palavras de Txai Macêdo sobre o primeiro contato com nosso povo Puyanawa:

Os primeiros Puyanawa que eu tive contato sem saber de que etnias eles eram, não sabiam que eles eram indígenas, mas que eram uma diferença dentro do exército, foi no exército lá no batalhão de engenharia e construção em Cruzeiro do Sul, onde encontrei o Dadá que é irmão do Mario, e encontrei o Chico da Alice que é irmão dele, mas não sabia, não sabia que eles eram índios, não sabia o nome da etnia deles, só sabia que eles eram diferentes dos outros. Mas eles também não sabiam se identificar. Depois que tomamos conhecimento, Terri e eu, de que Delvair Melatti, a antropóloga em 1977 tinha feito uma pesquisa, um trabalho para FUNAI e tinha delimitado várias terras indígenas na região e uma delas era a terra indígena Puyanawa, sob informações de Candido Rondon. Recorremos ajuda e conseguimos apoio a duas passagens e fomos para Cruzeiro do Sul para encontrar os Puyanawa. Isso aconteceu em 1983. Chegando a Cruzeiro do Sul, procuramos pessoas que conheciam eles e encontramos Mâncio Neto, neto de Mâncio Lima. Ele falou que lá no Barão, lá onde ele era o dono, lá tinha uns caboclos, mas não sabia que caboclos eram. Mâncio Neto nos levou para conhecer eles, ficamos sabendo do seu Camilo e dona Railda. Nosso primeiro contato direto com os Puyanawa na tribo foi em 27 de setembro de 1983, aí chegamos lá e como de costume, como a antropologia comanda, nós fizemos uma visita em cada casa. Obtivemos várias informações do convívio, das relações ali entre as famílias, os patrões, os meios de defesa, garantia, afirmação da 
comunidade tudo isso era fragilizado porque a comunidade não sabia nada sobre seus direitos.

No ano de 1983, a fazenda Barão ainda era dominada pelos herdeiros do coronel: Débora Lima, Raimundo dos Santos Lima e José dos Santos. Segundo algumas informações colhidas, os dois últimos eram netos do coronel, filhos do primeiro casamento de Mâncio Lima. Em virtude disso, os dois reivindicaram seus "direitos" junto a Débora, ganharam o processo na justiça e tomaram posse de algumas estradas de seringa. O comércio e as propriedades estavam dentro da área indígena. Os dois questionaram a parte do seringal e ganharam algumas estradas, além disso, a parte do Ipiranga pertencia a eles.

O sertanista Antônio Macêdo e o antropólogo Terri Vale de Aquino destacaram-se junto ao nosso povo atuando principalmente na mobilização, escrita, divulgação e no envio de vários documentos ao governo. Porém, os ânimos começaram a se acirrar, como conta Txai Macêdo:

Areunião foi feita na casa do terreiro do Mario com o seu Morais. Todos os Puyanawa que estavam ali foram para a reunião e lá informamos a eles que o direito deles existia e o mapa que estava incorreto íamos pedir correção. Mas que eles precisavam de representante, não tinham liderança. A comunidade elegeu o Mário e seu Ozeas, como vice do Mário. Mas quem assumiu o cargo de vice foi o seu Alberto Itxuwãy (indígena da época do contato). Aí começa-se uma luta, escrevemos um documento para a Funai reivindicando os limites de divisão da terra. A Funai mandou um grupo lá liderado pelo antropólogo Luis Carlos Levinho. Depois disso, eu fui lá para implantar uma cantina alternativa para os Puyanawa como instrumento alternativo, com recurso do meu bolso e do Terri, porque os patrões começaram a cortar todos os créditos deles, quando eles começaram a reivindicar seus direitos. No dia da implantação da cantina, foi um dia em que eu escapei fedendo, quase morri porque Mâncio Neto armou doze homens e ali, na frente daquele barracão antigo que tinha, estavam os doze homens armados com a arma apontada para mim. Eu levava comigo o jornalista Altino Machado, que era a primeira viagem dele e reportagem como jornalista. Para chegar lá, eu tive que, forçado pela polícia militar, levar dois soldados por segurança. Foi uma luta muito interessante porque só não aconteceu o pior porque o irmão de Mâncio Neto, Paulo Dene tinha acabado de voltar da cidade do Rio de Janeiro como arquiteto formado e se acocorou entre eu e Mâncio Neto, no meio da estrada, e pedia pelo amor de Deus que Mâncio Neto não me matasse porque o inimigo de Mâncio Neto não era eu, mas o governo.

Era algo comum, os patrões da borracha enviarem seus filhos para outros Estados e até para fora do país. Mâncio Lima é reconhecido pela literatura e pela 
maioria dos acreanos como um grande progressista e desenvolvimentista. Seu filho, Rubéns de Lima, escreveu um artigo chamado "Em Memória de Mâncio Lima", onde enaltece e engrandece os serviços de seu pai e contraria o trabalho dos antropólogos e a história Puyanawa.

Mâncio Lima (Cel. Da Guarda Nacional) participou da fundação de Cruzeiro do Sul e integrou-se à região com todo idealismo que the era peculiar, tornando-se seu líder maior. Impulsionando seu desenvolvimento político, social, econômico e cultural. Várias vezes e em épocas diversas exerceu altas funções de intendente e de prefeito de Cruzeiro do Sul, somando 12 anos de proveitosa administração: dispondo de poucos recursos desenvolveu a agricultura e dedicou cuidados especiais à Educação e Saúde Pública. As atividades de Mâncio Lima não foram restritas aos períodos à frente do governo municipal: dedicou-se toda sua vida integralmente a região: foi colonizador, pioneiro da aviação no Juruá, político idealista e progressista sempre atento aos problemas sociais da região (Lima 1983: 167).

O coronel de barranco nada investiu em nosso povo, há não ser a exploração e os rigorosos castigos para aqueles que desobedecessem suas ordens. Alguns indígenas the chamavam de "compadre" e seus filhos de "irmãos". Muitos the chamavam de "papai Mâncio". Porém, o único investimento de Mâncio Lima para com o povo Puyanawa foi a exploração e mão-de-obra escrava. Rubens de Lima, filho de Mâncio Lima distorce a versão contada pelos Puyanawa:

Lembro-me como se fosse hoje, do curumim Elizeu, porque sentávamos na mesma carteira de 4 lugares. Era esse o "cativeiro" denunciado pelos entrevistadores, que Mâncio Lima proporcionava às crianças poianaus do seringal. Muitos destes curumins se alfabetizaram, se emanciparam e hoje são eleitores. Alguns alcançaram posição de destaque no seringal, como encarregados de serviços ou até mesmo de auxiliar de escritório" (Lima 1983: 2).

São poucos os indígenas que conseguiram projeção social, restringindo-se isso a famílias que auxiliaram em conquistas militares e foram agraciadas com sesmarias e distinções especiais (Arariboia é o exemplo mais evidente disso). Em outros momentos da história do Brasil em que o território e a soberania estiveram em disputa, mecanismos de prestígio e relativa mobilidade foram atribuídos a outras personalidades indígenas. Outro caso bastante notório ocorreu na luta contra os holandeses em que se destacou a figura de Antônio Filipe Camarão (Pacheco de Oliveira 2016).

9 Compadre: Muitos Puyanawa lhe chamavam por seu Mâncio, compadre e "papai". 
No dia 13 de Junho de 2018, tive a feliz oportunidade de conhecer e entrevistar a antropóloga Delvair Montagner, que em 1977, a serviço da FUNAI, andava por terras acreanas fazendo um trabalho de identificação de grupos e escreveu o primeiro relatório de identificação da(TI) Puyanawa. De 1970 a 1980, a Funai foi muito produtiva. Segundo a antropóloga, o Acre era um desconhecido: "Erámos até pobre demais". A estrutura social Puyanawa estava esfacelada. Funcionava um sistema semelhante ao feudalismo, a descentralização e dispersão do povo representavam um grande problema a ser enfrentado.

Visando identificar grupos indígenas, Delvair colheu várias informações com o ancião já falecido, Cândido Rondon. Ele era conhecedor de todo trabalho e de todo movimento que se fizera até ali; sabia da história, da cultura, dos costumes e das tradições Puyanawa. Através das informações, em Brasília construíram um mapa delimitando uma área de 15.200 hectares. Em 1983, as informações foram corrigidas pelo antropólogo Terri Valle de Aquino e pelo sertanista Antônio Macêdo.

A antropóloga estava fazendo um levantamento, localização, ou seja, identificando onde havia "índios", procurando informações sobre a situação desses povos. Era um trabalho bastante pioneiro. Na Terra Puyanawa, ela visitou o engenho de cana-de-açúcar, pois o que mais funcionava era a agricultura. Segundo a antropóloga, A fazenda Barão do Rio Branco ${ }^{10}$ era muito comum, não tinha nada de poder ou riqueza, e a infraestrutura era muito pequena.

Vejamos abaixo o relato de Montagner:

Fomos bem tratados pelo usurpador, que se dizia o dono da fazenda, aí explicamos que erámos da Finai, que estávamos fazendo um trabalho e que posteriormente viria alguém para ver quem seria indenizado, as benfeitorias. Fizemos um levantamento demográfico da situação, mas o foco não era antropologia, o foco era visando uma futura demarcação. Estávamos preocupados sobre a relação com o fazendeiro, o que eles pretendiam fazer no futuro e até onde que a Funai poderia ajudar na construção dos trabalhos. Ninguém tinha pisado nos Puyanawa, ninguém nem sabia que vocês existiam. (Delvair Montagner, entrevista, 2018)

\subsection{O Processo de Demarcação}

Na década de 1980, os Puyanawa possuíam dois chefes que tinham a função de representar o grupo junto à sociedade nacional. Destaca-se a Associação Agroextrativista Puyanawa do Barão e Ipiranga (AAPBI), criada em 1988 para apoiar as lideranças, além de garantir à comunidade acesso a benefícios por meio de projetos com financiamento externo (Gondim 2002).

10 Fazenda Barão do Rio Branco: Nome dado ao que hoje é a Terra Indígena Puyanawa. 
A luta que se fez para que meu povo tivesse o direito garantido a terra não foi nada fácil. Após a morte de Mâncio Lima, pudemos plantar e criar, mas tínhamos que pagar renda para os "herdeiros" do coronel, Armédio e Débora. Os Puyanawa pareciam livres do regime de servidão a que foram submetidos, mas continuavam morando na sua terra como se fossem intrusos e sem direito a nada. Tudo o que produziam, deveria pertencer a Débora, principalmente a borracha. Poitxo relata que quando Débora enfraqueceu um pouco, seus filhos Paulo Dene, Alfredo Dene e Mâncio Neto passaram a liderar. A dominação sobre nosso povo parecia que nunca ia ter fim. De uma forma ou de outra, sempre estávamos submetidos a ela.

"Nessa época que eles vieram, piorou um pouco porque todo mundo já criava porco aqui, já faziam suas plantações. Os filhos de Débora começaram a pegar dinheiro, a fazer empréstimo nos bancos e explorar terra onde as pessoas trabalhavam. Começaram a fazer campo para criar gado e chegou uma época que eles mataram os bichos dos criadores, achavam que ninguém tinha direito a nada, era deles, eles faziam o que quisessem". (Poitxo, entrevista, 2016)

O processo de Demarcação da Terra Indígena Puyanawa, não foi nada fácil. O cacique emérito Mario Cordeiro de Lima, que na língua Puyanawa é chamado de Hawê "jabuti", tinha o sonho de demarcar a terra. O antropólogo Terri Vale de Aquino conta que foi convidado pelo chefe indígena, Mário Cordeiro de Lima, carinhosamente chamado "Jabuti" por toda a nossa comunidade, para documentar, testemunhar, discutir e animar o pessoal da demarcação, registrar fotos do trabalho, e escrever cartas e relatórios para as pessoas e entidades que ajudaram com recursos financeiros e apoio político a esse acontecimento importante na história Puyanawa.

A demarcação começou a se materializar quando Terri Aquino passou quarenta dias junto com nosso povo, participando da vida cotidiana, indo aos roçados e colocações de seringa, trabalhando com seu terçadinho lá nos fundos do Seringal, subindo e descendo as terras dos divisores de água, pescando nos igarapés de águas negras e piscosas, tomando cipó (hêu) nas noites de lua e jogando futebol nos finais de semana. Enfim, trabalhando e brincando de índio com os txais da floresta ${ }^{11}$. Fazia tempo que o cacique Mário Hawê tinha recebido um sonho de demarcar nossa terra junto com toda a comunidade.

Em maio de 1990, o sertanista Antônio Macêdo, do Conselho Nacional dos Seringueiros, recebeu um majestoso convite internacional para participação numa grande conferência, porém disse que somente ia se levasse um representante indígena. $\mathrm{O}$ cacique Mário Hawê foi escolhido e o povo se reuniu

11 Txais da floresta: Nome dado aos indígenas acreanos. É comum no Acre os indígenas se tratarem por Txai: parente/amigo. 
para lhe ajudar com pequenos recursos, como conta Luís Clemente (Kupati):

Já estávamos mais ou menos sabendo dos detalhes, só que cada qual mais interessado para o Mario ir. Tive que vender um porco para ele ir fazer a viagem dele e trazer o resultado aqui para nós. Naquele tempo existia união, tudo que ele ia buscar repassava para nós. No começo era assim, até que conquistamos nosso direito da terra, mas foi com dificuldades, com brigas, com lutas, sem ter recursos para quase nada, mas graças a Deus, que hoje todo mundo vê isso. Naquele tempo o conjunto era outro, tinha lideranças velhas, finado Alberto, Finado Antimá, minha mãe, tia Marga. (Luís Clemente, entrevista, 2019)

$\mathrm{Na}$ grande viagem a Noruega e Inglaterra, através do sertanista Antônio Macêdo, o cacique Mario Hawê conseguiu uma pequena ajuda no valor de $5 \mathrm{mil}$ dólares do empresário inglês, Fred Mulder, amigo do príncipe Charles. O recurso advindo do exterior proporcionou a efetivação do processo da autodemarcação realizada pelos próprios Puyanawa.

A autodemarcação foi um processo que durou três semanas, com a participação de vários membros do nosso povo e alguns não-indígenas (dawa), coordenados pelo mateiro ${ }^{12}$ chefe e uma das figuras mais carismáticas e sorridentes que já conheci, o falecido Ozeas Correa ( $a w a)$, que infelizmente nos deixou em 2017. Portanto, os vagarosos passos para a retomada definitiva estavam se concretizando- após muitos anos de luta: "Tinha havido várias tentativas, mas só em julho de 1990 a área indígena foi auto-demarcada, sendo necessário ainda seu reconhecimento por parte da FUNAI" (De Paulla 1992).

Antes de concluir essa seção, não posso deixar de falar sobre a importância e o protagonismo das mulheres Puyanawa, que na época dos conflitos, tiveram uma relevante participação fazendo frente ao seringalista Manoel Lopes. Sófia Lopes Itxapukê, Dona Raimundinha, tia Bim e outras ficaram de mãos dadas impedindo os patrões passarem para os seringais. Sinto enorme carinho por todas elas, principalmente pela anciã e titia (yaya) Railda Mãdaitá, uma pessoa amável, atenciosa e lúcida, que já em seus 87 anos, é a principal síntese de conhecimento cultural e linguístico para o nosso povo.

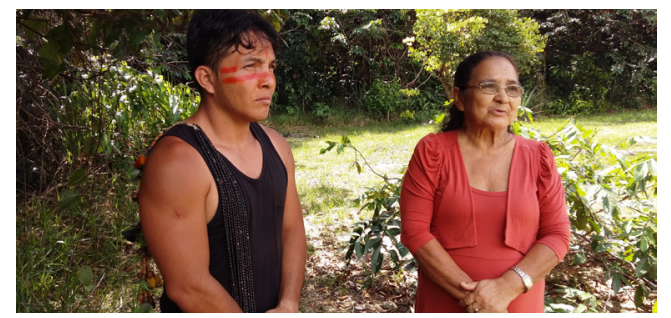

12 Mateiro: abria estradas de seringa, corrigia as estradas, tinha um grande conhecimento sobre as matas. 


\section{Imagem 1: Com titia (yaya) Sófia Itxapukê, neta de Wêwakãy, narrando estórias acontecimentos e o processo de demarcação.}

Segundo algumas informações colhidas, dos próprios Puyanawa, o atual cacique Joel Xay Nay, filho do cacique emérito Mario Hawê, atuava como um porta-voz dos "recados" para os mais velhos, repassando importantes informações sobre o dia em que aconteceriam as reuniões, sem o consentimento dos patrões.

Os patrões não concordavam com a ação da FUNAI, portanto, a instituição fez um levantamento dos não-indígenas (dawa) e a partir de 1986 foram pagas as indenizações. Porém, muitos não concordaram com as benfeitorias reconhecidas pelo Governo, chegando até a questionar. Durante esse período de luta, houve a estruturação de muitos elementos e políticas. Deixamos principalmente de pagar renda, pois os produtos já podiam ser vendidos em Mâncio Lima e Cruzeiro do Sul.

Finalmente, após muitos anos de luta, conflitos, falecimentos, resistência e superação, em 2000, a FUNAI conseguiu demarcar a terra através do Projeto Integrado de Proteção às Populações de Terras Indígenas e da Amazônia LegalPPTAL, que foi repassado pelo governo brasileiro.

Depois da terra demarcada, conseguimos nos organizar cada vez mais. Foi uma coisa interessante porque, depois da demarcação da terra, eu com esse tempo todo de luta, resolvi passar as decisões de chefia para meu filho Joel coordenar o nosso povo. Com a terra demarcada tínhamos que assumir o trabalho que estava já feito e a fiscalização da terra, para não ser invadida pelos não-índios, Mário Hawê.

Vários anos se passaram desde a primeira visita da antropóloga Delvair Montagner, e todos os Puyanawa da época do contato e outros que bravamente lutaram para consolidação de nosso direito ancestral, já faleceram, mas firmemente deixaram seus legados. Muitas vezes, fico horas pensando como foi a luta de meus ancestrais para garantir a efetivação do direito à terra. Por isso, me propus a escrever esse pequeno artigo, trazendo relatos, elementos e ações de todos aqueles que cooperaram e participaram ativamente da luta para o processo de demarcação da Terra Indígena Puyanawa.

Hoje em dia vivemos num território constitucionalmente demarcado, vivendo nosso modo próprio de viver. Somos os maiores produtores de farinha do município e mantemos relações amistosas com várias comunidades próximas. Atualmente temos nos destacado no cenário cultural, social, político e econômico, com a construção da arena Puyanawa (êwê dimanã yubabu), que proporciona inúmeros eventos e visitas. Infelizmente ainda continuamos alvo de inúmeros ataques e retrocessos, pois recentemente recebemos a visita do ministro do Meio Ambiente, Ricardo Salles, onde discutimos a construção 
da rodovia internacional, que irá passar próximo a nossa terra. Certamente a construção dessa rodovia irá nos afetar, mas continuaremos lutando firmemente pela preservação das nossas tradições e nosso território.

\section{Referências}

Constant, Jósimo. 2018. História, Memória, Conhecimentos Tradicionais e as Desafiadoras Mudanças Climáticas Sob o Olhar da Perspectiva Indígena Puyanawa.

Giroux, Henry A. 1995. Memória e Pedagogia no maravilhoso mundo da Disney.

In:SILVA, Tomaz Tadeu da. (Org.). Alienígenas na sala de aula: uma introdução aos estudos culturais em educação. Petrópolis, RJ: Vozes, p.132-158.

Godim, Sergio Augusto de Albuquerque. 2002. Poyanáwa: sabedoria e resistência. In: Povos do Acre. _História Indígena da Amazônia Ocidental. Ed. Fundação de Cultura e Comunicação Elias Mansour (FEM). Rio Branco, Acre.

Lima, Rubens de. 1983. Índios que Mâncio Lima Catequisou.

Pacheco de Oliveira, João. 2018. O Nascimento do Brasil e Suas Raízes "pacificação", regime tutelar e formação de alteridades, 2016.

Rosso Walker, Maristela. 2012. A Identidade Puyanawa e a Escola Indígena.

Santos de Paula, Aldir. 1992. Poyanawa, A Língua dos Índios da Aldeia Barão: Fonologia e Aspectos Fonológicos e Morfológicos. 